\title{
Freedom of Speech in Modern Political Culture
}

\author{
Justyna Miklaszewska \\ Jagiellonian University, Cracow, Poland \\ justyna.miklaszewska@uj.edu.pl
}

Received 16 September 2018; accepted 28 January 2019; published 30 June 2019.

\begin{abstract}
In the philosophy of liberalism, freedom of speech is one of the fundamental rights of the individual, one that is guaranteed by the constitution of a liberal democratic state. Contemporary Western democracies are based on the political culture in which human rights, including the right to free speech, play an important role. This right, however, can be violated by demagogic propaganda both in totalitarian regimes and in democracies. The propaganda mechanism, reaching into the sphere of community values and concepts, presently operates also through the Internet, in which expressions of anger and hatred are disseminated and can lead to the destruction of democracy. I will argue that, in today's world, restrictions on the freedom of speech through legal norms are necessary, because the threat comes not only in the form of censorship, but also the manipulation techniques used by politicians in democratic regimes. Advances in modern technology can be of service to dictatorship when the media and the Internet are used for propaganda or surveillance purposes, but they also provide a support to freedom and democracy when they serve as the means of the transmission of reliable information, initiating public discussions. As such, they establish a framework for rational debates and peaceful activities that contribute to the maintenance of the democratic political culture. The basic elements of this culture, i.e. legal rules, pluralist media, and education systems are all necessary for the defence of its core value, namely the freedom of speech.
\end{abstract}

Keywords: freedom of speech; propaganda; hate speech; democracy; liberalism.

\section{Liberalism and Freedom of Speech}

Contemporary liberal-democratic societies are based on a political culture that has evolved in the modern era and embraces a common system of values. Human rights play an important role in this system and among them the freedom of speech, which together with other political freedoms, is one of the fundamental rights of an individual. This conviction 
found expression in numerous declarations and constitutions, beginning with Article XI of the Declaration of the Rights of Man and the Citizen (1789), which stated that, "The free communication of ideas and opinions is one of the most precious of the rights of man".

In the work of philosophers of the liberal tradition, the right of a citizen to freely proclaim their views is seen as self-evident and treated also as a good that should be equally guaranteed to all citizens of a democratic state. In practice, the scope and validity of this right both depend on the state: liberal democracy is popularly believed to guarantee the highest level of freedom, while totalitarianism does just the opposite.

Among the many reasons that justify the right to freedom of speech, two arguments are of particular significance. The first one was formulated in the $17^{\text {th }}$ century by Benedict Spinoza, who argued in the Theologico-Political Treatise that this freedom allows citizens to articulate problems which are unnoticed or neglected by the rulers, thus preventing social unrest. According to him, the freedom to express critical opinions is beneficial, because it contributes to the improvement of the state and as such should not be restricted in any political system, even in a despotic regime, provided that it does not lead to rebellious actions (Spinoza, 1670/2004, p. 258).

The second argument comes from John Rawls, who argues that allowing individuals the freedom of speech is not only a requirement of social justice, but also a prerequisite for rational politics to be implemented in the state. Similarly to John Stuart Mill, Rawls points out that freedom alone does not guarantee rational politics, but its absence means that politics is subordinated to particular interests of individuals or social groups. He puts freedom of speech within the framework of the first principle of justice, which also includes other freedoms that are equally guaranteed to all citizens, for we are all equal as moral persons, for whom the government should secure "the fair value of political liberty" (Rawls, 1999a, pp. 197-198).

Indeed, Mill was one of the defenders of unrestricted freedom of speech. In the second chapter of his essay, On Liberty (Mill, 1859/2001), he states that if even one human being had a different opinion than the whole humanity, the latter would not be entitled to silence the one individual.

If all mankind minus one, were of one opinion, and only one person were of the contrary opinion, mankind would be no more justified in silencing that one person, than he, if he had the power, would be justified in silencing mankind. (Mill, 1859/2001, p. 18)

Even if this opinion is wrong, he further argues, society achieves "a benefit, the clearer perception and livelier impression of truth, produced by its collision with error" (Mill, 1859/2001, p. 19). A similar argument has been developed by Thomas Scanlon, who claims that freedom of expression should be free from interference even if it leads to obvious and significant harms (Scanlon, 1972, p. 216). Undoubtedly, this claim goes against the common-sense view, according to which the state is responsible for the citizens' safety. 
This claim is not accepted by Scanlon, who excludes the possibility of the state interference with any act of expression; he asserts that rational and autonomous individuals bear responsibility for their actions and cannot transfer it to others (Amdur, 1980, p. 291).

However, considering freedom of expression in the broader context of political liberties, one can look at this issue from another angle, namely that there is no absolute freedom and acting persons are always confronted with the limits of their choices due to economic conditions, their capacities, the political situation, etc. With regard to the freedom of speech, these restrictions appear in the form of ethical self-constraints or legal norms. The first kind of constraints is related to religious beliefs and the cultural background, while the scope of the second one depends on the political regime. However, it is quite often the case in a liberal democracy that freedom of speech is restricted by the ban on speech which would harm other citizens or impinge on the stability of the state (Rawls, 1993, p. 336). In this political regime, however, even these forms of restrictions essentially depend on the self-constraining power of individuals, who limit their freedom voluntarily by making choices about constraints to be imposed by the constitution and the law.

I will argue that, in today's world, some restrictions on the freedom of speech are necessary, especially through legal norms, because it is not only totalitarian censorship - seeking to silence the citizens - that poses a threat, but manipulation techniques that are used by politicians in democratic regimes are also dangerous. The unstable character of democracy and the possibility of it being turned into tyranny by means of abusing the freedom of speech by demagogues had already been pointed out by Plato, Aristotle, and JeanJacques Rousseau. Presently, this process is related primarily to how the Internet functions, i.e. expressions of anger and hatred are disseminated and can lead to the destruction of liberal democracy. This is mainly due to the phenomenon of hate speech, especially in social media, which strengthens the existing divisions in society and tends to incite acts of violence. As a result, members of conflicted groups are unwilling or afraid to engage in a democratic discourse. In particular, new democracies are susceptible to these actions that push them towards the so-called illiberal democracy (Zakaria, 1997). Thus, there is an important factor, which I shall concentrate on, namely the latest techniques and methods of propaganda that can destroy the freedom of thought unless they are prevented by laws created within the political culture of a democratic society. Although propaganda is a phenomenon that has been observed in many societies for some time now, today it assumes new and dangerous forms, all of which should be examined thoroughly.

\section{The Phenomenon of Propaganda}

In a broad sense, propaganda can be described in terms of spreading particular ideas in society for the sole purpose of popularizing them. More specifically, it involves deliberate manipulation and forcing people to perform some kind of action by using media and the tools of social communication. In this latter, political sense, this concept takes on a pejorative connotation; propaganda becomes involved in the relationship between freedom and 
power. Authoritarian political powers aim to destroy the freedom of the individual by means of language and, in consequence, propaganda makes freedom of speech a meaningless, blank concept. The destructive propaganda mechanism, however, also influences other spheres of social life, in which concepts that are crucial for the functioning of the community are subjected to manipulation and, as a result, change their meanings. According to Jason Stanley (2015, p. xiii), this political propaganda can be defined in terms of transforming certain ideas into their opposites; the paradigm of propaganda, he argues, is to present biased and subjective intentions as objectively valuable goals.

Thus, the phenomenon of propaganda analyzed in the political philosophy is an example of the interference of politics and politicians with private lives of individuals. It involves imposing on citizens a world-view that falsifies reality and forces them to exhibit particular behaviors. The real goal is for a politician or a political party to gain or maintain power through the medium of language (speech, script, or image), which results in a deceptive image of reality being transferred to the public.

Propaganda works not only by means of changing the meaning of concepts, but also by repeating them frequently in the public domain, e.g. during speeches delivered at political rallies, but primarily in the press, television, and the Internet. Propaganda also reaches the domain of art: literature, film, and theater, but the most powerful impact is achieved with the use of media (especially the public media), provided that they are widely available and used. The effectiveness of propaganda can therefore be strengthened by the monopolization of the mass media by the state or the subjection of independent sources of information to restrictive control, which, de facto, affects the citizens' freedom by restricting their freedom of choice.

Although the phenomenon of propaganda has been known for ages, the notion itself emerged in the $17^{\text {th }}$ century and it did not have a pejorative meaning. At the beginning of that century, during the Counter-Reformation, the Catholic Church began to intensively propagate the principles of faith. Under the name of propaganda, the writings of Rome aimed to popularize religious contents among the masses, constituting their religious education. Another example of propagandist actions was the political life of the $18^{\text {th }}$-century England, where the overwhelming propagation of the myth of the imperial power of the British Empire was taking place. In the next century, on the other hand, one could observe strong propagandist agitation in the opposite direction, i.e. in the writings of anarchists that popularized the idea of abolishing the state. At the beginning of the $20^{\text {th }}$ century, however, a significant change occurred; due to the development of mass media, propaganda became a tool of totalitarian power. In all these regimes, the meaning and function of propaganda was completely reversed and ceased to serve its initial positive purpose. In other words, the propagation of useful contents changed into the propagation of half-truths and lies, encouraging harmful actions. This is how the concept came to carry negative connotations. 


\section{Propaganda and Totalitarianism}

The goal of propaganda in totalitarian systems is to attain and maintain power by means of language; therefore, this phenomenon was analyzed by linguists, first of all by Victor Klemperer in his classic book: LTI: Lingua Tertii Imperii, The Language of the Third Reich (Klemperer, 1947/2010). Written during the war by a Jewish professor living in Dresden, it contains an analysis of the methods of the Nazi propaganda that altered the German language to propagate National Socialist ideas, which were subsequently assimilated both by the masses and by fascist intellectuals. In his work, Klemperer gives numerous examples of newly created words and abbreviations, and describes the application of well-known concepts in a new context with altered meanings. In doing so, the author describes a universal system of propaganda language; based on lies, it is not restricted only to fascist Germany. This system was primarily meant to reach the masses that, according to the propagandists, are to be made incapable of independent thinking.

Klemperer's analysis of the language of the Third Reich goes beyond linguistics and becomes a political theory of the totalitarian system in its fascist version, just as George Orwell's dystopian novel, titled 1984, contains a concise description of communism with its characteristic language, i.e. newspeak. The word denotes the language of communist propaganda, which aims not only at spreading certain ideas, but also at eradicating alternative contents and ways of thinking. As a result, the ideas condemned by the official ideology, such as the notion of freedom, could not be expressed in this newly created language (Orwell, 1981, p. 241). This shows the specific nature of the totalitarian propaganda, which not only influences the human activity, but also interferes with the sphere of human thinking.

The propaganda mechanism, which is inherently present in newspeak, is described by Orwell as a form of dialectical thinking. The basic principle of totalitarian propaganda is that "white is black and black is white". It involves the reversal of the established meaning of concepts and resorting to lies in order to maintain control over individual human minds. Thought and speech are both subjected to the distorted ideology and policy of the state, and freedom becomes an empty notion or an equivalent to slavery. Indeed, Orwell's 1984 presents the analysis of totalitarianism as a system that governs through propaganda, surveillance, and violence. Newspeak, in which the meanings of words are turned into their opposites, creates a false image of reality.

\section{Post-Truth Politics}

Jean-Jacques Rousseau was one of the first thinkers in the modern democratic tradition to pay attention to the mechanism of language deformation as observed in the majority of modern societies. In Discourse on the Arts and Sciences (1750), he stated that children in schools recited poems mindlessly, misunderstanding words such as generosity, humankind, or justice, which had all lost their original meanings. In the philosopher's pessimistic view, modern society is no longer a community of people who think independently, but, rather, is treated by the government like a herd. 
Adam Mickiewicz, who was an outstanding Polish romantic poet, also drew attention to propaganda techniques. In a poem titled Why He Lies, Satan deliberately spreads lies among people, because he himself wants to believe in them. In the $20^{\text {th }}$ century, a similarly perverse principle that "a lie repeated a thousand times becomes the truth" was turned into a method of ruling the country by Joseph Goebbels, the Nazi minister of propaganda. Nowadays, political philosophy considers a lie as a kind of destructive propaganda which disrupts the process of transmitting information within society, producing harmful effects on the community (Shiffrin, 2014; Stanley, 2015, p. 57). In contemporary liberal democracies, one can observe a political strategy based on lies, which is now called the 'politics of post-truth'. This strategy, used predominantly in election campaigns, is supported by the Internet and the spreading of unreliable information.

A columnist of The Economist (2016) in an article "The Post-truth World" defines posttruth politics as "the art of the lie" claiming that contemporary politicians who use this special language are not bothered with the truth of their statements, but, instead, they rely on feelings and prejudices to present counter-factual opinions. They hope that, due to the media and the Internet, these opinions will be repeated and widely disseminated so that they can achieve their intended goals. Their aim, however, is not to create a false worldview, as was the case with old propaganda strategies, but, rather, to establish prejudices. This is made possible by the evolution of the media and the fragmentation of news sources, and, as a result, lies which are shared online become reliable information. Post-truth political discourse can be found e.g. in the last American election campaign, in propaganda speeches in Great Britain before Brexit, and in statements made by some Polish politicians, which suggests a plot between the post-communist leaders and the former communist regime. They also exist in declarations made by the Russian president, who denied the presence of Russian soldiers in Ukraine during the recent invasion of Crimea.

This post-truth politics is possible mainly due to the loss of trust in democratic institutions of the Western world. People are looking for 'authentic politicians' and are more inclined to trust to the man in the street than a minister or journalist. However, there is also another important reason, namely the growth of the Internet. The overwhelming majority of people in many countries, including Poland, get news from the social media, where contents are not presented in fixed formats, like it is in a newspaper article, for which the author is personally responsible. This phenomenon is accompanied by the expression of anger and hatred of some Internet users, which can lead to acts of violence. In contemporary liberal democracies, freedom of speech is threatened with the abusive language of hate speech and lies used deliberately in order to discredit some people and some views. This is why it is so important to introduce legal restrictions on the freedom of speech, especially those related to the Internet, whose participants often have a sense of anonymity and impunity.

In order to counter this post-truth strategy, it is necessary to perform actions requiring courage, such as exposing liars both in the old and the new media, and bringing them to trial. This undoubtedly difficult task of distinguishing the civic courage of revealing real facts to the public from spreading fake news should be left to independent courts. Thus, 
the important thing is to work towards the establishment of a political culture that cares about truth and to obey the rules of democratic public discourse. In particular, the public debate among political opponents cannot be an expression of their negative emotions. On the contrary, its participants should fulfill the basic requirement to present their reasons with respect to the dignity of their opponents and look for a common ground that would make it possible to reach an agreement.

Jürgen Habermas (1991), who diagnosed this problem in his works, describes and severely criticizes the manipulative use of media power in the public sphere, whose objective is to win the loyalty of the masses. According to him, speech communication between people in a society goes through special channels that must be protected from lies and biased or incomplete messages. The purpose of this protection, which is primarily legal, is to ensure the reliability of the information provided. Indeed, the protection of social communication from propaganda activities is at the same time a defense of the fundamental democratic value of the freedom of speech. Thus, a person spreading misleading information in a society cannot claim the right to free speech, just as scholars must not falsify the results of their research.

\section{Propaganda in a Democratic State}

It is clear that propaganda is not limited to totalitarian states, but, in various forms, it is also present in the democratic world, constituting the subject of both popular interest and scientific research.

In 2013, there was an exhibition at the British Library, titled Propaganda Power and Persuasion, in which various items from the last few centuries were demonstrated, with a special focus being on the propaganda of the $20^{\text {th }}$ century. The organizers emphasized the ambiguity in the evaluation of some political activities that could be differently assessed from the opposite points of view, but which influenced their classification as propagandist actions. For example, the propaganda of the army is a lie from the perspective of a pacifist, because war is evil but the matter looks different from the point of view of the state. During the First World War, Germany attempted to dissuade Americans from joining the war. They spread the idea of isolationism, which discouraged U.S. citizens from interfering with matters that were not in their interest (Cooke, 2016). After the war, however, when it turned out that America had profited from it, posters were published in Europe, showing Europeans fighting and American capitalists becoming rich. This example proves that it is sometimes difficult to draw a thick line between truth and falsehood.

In public life today, biased interpretations of events in the media also take place and their purpose is to discredit some politicians, especially political opponents in election campaigns. Such activities are based on the conviction that members of society are unable to think independently and, therefore, it is necessary to provide untrue or selective information, thereby forming support for one's own party. These actions, however, distort and hinder the objective assessment of the political facts by citizens, thus destroying the 
democratic process of public decision-making based on collected information. Such propaganda often makes references to national memory, particularly by means of disseminating a biased interpretation of historical events, which leads to social divisions and conflicts.

As Jason Stanley observes (Stanley, 2015, p. 27), propaganda is much more difficult to grasp in a democratic society than in a totalitarian regime, since it often takes on a masked form. Obviously, one should not condemn the practices of public relations, which involve the propagation of useful contents or the actions of politicians promoting their image so that voters can be wooed. Derived from business practices and advertising, the concept of public relations has been introduced into the political life in order to distinguish positive actions from propaganda, which has negative connotations. Unlike Habermas, who criticizes the negative propagandist actions of market advertising that make use of manipulation techniques (Habermas, 1991, p. 186), Stanley focuses on political propaganda and demagoguery that accompanies it.

The contemporary liberal democracy is based on fundamental institutions, such as political campaigns, lobbyists, free media. All of them use specific propaganda language in order to influence the way citizens deal with public matters. The conviction that the manipulation of the public opinion is restricted to the past is erroneous, although it probably does not play as great a role in modern democracies as it did in the totalitarian systems of the $20^{\text {th }}$ century, because there are many centers that disseminate propagandist ideas. However, propaganda in the democratic world today works in a more subtle way and, by violating the mechanisms of a democratic debate, it destroys the values of the community.

The functioning of propaganda is currently based on the misuse of the democratic vocabulary towards achieving certain goals for the sake of political manipulators and demagogues. In the socialist countries of the $20^{\text {th }}$ century, the language of democracy was used as a veil for the non-democratic system. Similar examples of the demagogic use of language are now present in Western democracies in various forms. For example, in the last election campaign in France, the far-right party leader presented herself as a defender of democratic values, using the language of "We, the people", but her political program was, in fact, anti-democratic.

The recognition of the mechanisms of propaganda and the ability to resist them are both crucial for the preservation of liberal democracies, since the subjection to manipulation can lead to unpredictable consequences, namely the annihilation of civil liberties and the transformation of these democracies into a dictatorship. Thus, the process of language communication in democratic societies should be protected from propaganda mechanisms that tend to destroy liberal democracies and the political culture of modernity.

\section{Freedom of Speech and Political Culture}

When considering freedom of speech, the emphasis is usually on freedom. It is, however, equally important to underline its direct complement, i.e. speech. Speech consists of words, while a word is a constituent element of language as the system which makes the 
processes of communication possible in a society. The basic function of a word is to transmit information, but it also has the power to influence individuals' choices by appealing to their reason or emotions. This relates to politics in particular, because the unethical use of words by the participants of the political life, some of whom are demagogues trained in the language of propaganda, destroys the ongoing communication process in a society.

The link between this process and the broader political culture of a society is highlighted by both Habermas and Rawls. They argue that an important part of social communication is discussion aimed at reaching an agreement between individuals, which is a necessary condition for a successful social cooperation. The distortion of this communication process in the name of either group interests or goals of a ruling party destroys the institutions of the democratic state. Although the contemporary deliberative democracy embraces a variety of conflicting interests, its institutions make it possible to reach a compromise that enables cooperation, whereas demagogic propaganda, in fact, destroys them. In contemporary societies there is also something on which all citizens can rely, namely the democratic political culture that is based on trust in people's reason and their ability to participate in public debates.

The concept of political culture itself has multiple meanings (Formisano, 2001). It has appeared in the works of contemporary historians, sociologists, and philosophers as a factor that has been shaping the Western societies since the age of the Enlightenment until today. However, John Rawls (1999b, p.152) characterizes public political culture as distinct from the background culture, i.e. a variety of comprehensive doctrines and social and religious beliefs. According to him, public political culture creates the basis for a public agreement on the one hand and the conception of political justice on the other. In consequence, this conception of justice as fairness, shared by citizens, expresses their public political reason (Rawls, 1993, p. 9). Thus, Rawls formulates the concept of public reason, rooted in public culture, which is the core element of modern democracy; its proper functioning guarantees the stability of the state. It manifests mainly in the institutions of a democratic state, but its effective functioning involves a public discussion in which arguments are presented in compliance with some established rules, which facilitates the reaching of an agreement. In practice, however, one can observe that this culture of public reasoning and public discussion is visible in liberal democracies with long tradition, while citizens living in young democracies are more susceptible to demagogic slogans and, in the name of liberty, some of them are inclined to accept illiberal democracy that ignores constitutional rules (Zakaria, 2007).

In addition, this Rawlsian approach to political culture and public reason as the foundations of liberal democracy presupposes a universal human ability to rational argumentation and expression of opinions in accordance with the rules of public debate. In contrast to this stance, Habermas defends freedom of speech as every individual's right, demanding the possibility of expressing opinions in a way that citizens choose to present them. Rawls partially agrees with Habermas, but he distinguishes between the presentation of the opinion and the argumentation in the public debates, which should adhere to the rules of rationality (Rawls, 1999b, p. 155). However, Rawls does not attach great importance to 
human emotions as he neglects their impact on the life of the community. This problem is analyzed by Martha Nussbaum $(2015 ; 2016)$, who stresses the destructive role of some negative emotions, such as anger or fear, in the social and political life, and believes that they can be neutralized in the education process. She also offers tools to address the fear: good principles, the overcoming of narcissistic consistency, and the cultivation of the capability of the "inner eyes" that enable people to understand the minority experience (Nussbaum, 2012, p. 59). Nussbaum does not use the term 'political culture', but she proposes a strategy of dealing with destructive forces in order to overcome them. As she writes:

In the contemporary world we need policies that follow the insights embedded in these principles, showing equal respect for all citizens by providing both ample and equal liberty, indeed the greatest liberty that is compatible with equal liberty for all and the preservation of vital public interests (such as peace and safety). (Nussbaum, 2012, p. 90)

The success of this political strategy in a society, however, depends on the existence of a broadly understood democratic political culture, i.e. one respecting human dignity and values such as individual freedom and peace. Therefore, it should also be stressed how essential educating the society is to the formation of this democratic political culture. Such education should be aimed at adult citizens, politicians, and journalists, countering violations against the freedom of speech committed by the authorities as well as the participants of Internet debates.

Advances in modern technology can undoubtedly be of service to dictatorship when the media and the Internet are used for propaganda or surveillance purposes, but they can also provide a great support to freedom and democracy. Both the Internet and independent media play a huge role in the transmission of information and the formation of public opinion through discussion. They also have a positive impact on the creation of social bonds and can provide the motivation to defend democracy. One of their important roles is to educate citizens so that their emotions can find an outlet for political expression in the form of rational debates and peaceful activities, which contribute to the maintenance of a democratic culture. The concern for freedom has to be associated with the ability to create legal instruments to prevent propaganda abuses in the political life, the media, and the Internet. On the one hand, democracy cannot function properly without the citizens being deeply attached to the concept of freedom. On the other, however, this should be accompanied by the ability to restrict it in the name of truth, ethical values, and legal rules. This applies primarily to the Internet, which, although it provides the greatest extent of freedom of speech, should also operate within the limits of the law.

Those who resort to lies, hatred, and contempt in the Internet or in the media should be penalized for making and promoting hate speech; this penalization should become a legal standard in all democratic societies. In this context, the question arises as to what criteria should be taken to determine whether a statement falls into the category of hate speech which would not destroy the fundamental civil right to the freedom of speech itself. What penalties should be introduced that would not prevent people from expressing their views and critical opinions with regard to the current government policy and ruling parties? 
There is no simple answer to these questions; any society should work out a solution that could be situated within the framework of the political culture of a democratic society.

Citizens have tools which make it possible to express and modify views by means of exchanging opinions in public debates performed in the media, on Internet platforms, during meetings in civil associations, or in the course of academic conferences, as well as by organizing special guest lectures in schools. Positive effects can be produced when the subjects of these debates refer to current difficult problems and when their participants come to accept, at least to some extent, views that are different from their own opinions. If a society succeeds in reaching a compromise and the proposed solutions are introduced by the government, citizens will have the feeling that they have been heard and that democracy is functioning properly. In other words, one of the basic human rights that comes in the form of the often repeated postulate of being heard by the government of a liberal democracy will be recognised and protected.

The most important issue seems to be about establishing the impartial legal rules that do not express the interests of a ruling political party, but, rather, are supported by the society as a whole, being applied as a result of a series of public discussions and political meetings. Apparently, in the legal framework of the EU such laws already exist and the member states should make their legal systems compatible with these general statements on the one hand and universal human rights on the other. This is part of an ongoing process of reaching balance between legislation and individual liberty, which takes place within the political culture of a democratic society that has also been transformed with time. Maintaining and developing this culture can be described in terms of a communication process between society and its rulers. It is important that this communication should go smoothly and lead to a mutual understanding and agreement, not to a rebellion or a civil war. Therefore, the widespread civic education and reliable and pluralistic media are all necessary so that citizens can cultivate a political culture that is essential for the proper functioning of democracy, including the defense of its core value, the freedom of speech.

\section{References}

Amdur, R. (1980). Scanlon on Freedom of Expression. Philosophy \& Public Affairs, 9(3), 287-300.

Cooke, I. (2016). Propaganda as a Weapon: Influencing Intellectual Opinion. Retrieved from www.bl.uk/world-war-one/articles/propaganda-as-a-weapon

Formisano, R. P. (2001). The Concept of Political Culture. The Journal of Interdisciplinary History, 31(3), 393-426. Retrieved from https://www.jstor.org/stable/207089

Habermas, J. (1991). The Structural Transformation of the Public Sphere: An Inquiry into a Category of Bourgeois Society. (T. Burger, Transl.). Cambridge, MA: The MIT Press.

Klemperer, V. (2010). The Language of the Third Reich. LTI: Lingua Tertii Imperii. A Philologist's Notebook. (M. Brady, Transl.). London, UK: Continuum. (Original work published 1947) 
Mill, J. S. (2001). On Liberty. Kitchener, ON: Batoche Books. (Original work published 1859)

Nussbaum, M. C. (2012). The New Religious Intolerance: Overcoming the Politics of Fear in an Anxious Age. Cambridge, MA: Harvard University Press.

Nussbaum M. C. (2015). Political Emotions: Why Love Matters for Justice. Cambridge, MA: Harvard University Press.

Nussbaum, M. C. (2016). Anger and Forgiveness: Resentment, Generosity, Justice. Oxford, UK: Oxford University Press.

Orwell, G. (1981). Nineteen Eighty-Four: Appendix. The Principles of Newspeak. Harmondsworth, UK: Penguin Books.

Rawls, J. (1993). Political Liberalism. New York, NY: Columbia University Press.

Rawls, J. (1999a). A Theory of Justice: Revised Edition. Cambridge, MA: Harvard University Press.

Rawls, J. (1999b). The Law of Peoples. Cambridge, MA: Harvard University Press.

Rousseau, J-J. (1750). Discourse on the Arts and Sciences. (G. D. H. Cole, Transl.). Retrieved from https://www.stmarys-ca.edu/sites/default/files/attachments/files/arts.pdf

Scanlon, T. (1972). A Theory of Freedom of Expression. Philosophy and Public Affairs, 1(2), 204226.

Shiffrin, S. V. (2014). Speech Matters: On Lying, Morality and the Law. Princeton, NJ: Princeton University Press.

Spinoza, B. (2004). A Theologico-Political Treatise and A Political Treatise. (R. H. M. Elwes, Transl.). Mineola, NY: Dower Publications. (Original work published 1670)

Stanley, J. (2015). How Propaganda Works. Princeton, NJ: Princeton University Press.

The Economist. (2016, September 10). The Post-truth World. The Economist, pp. 20-23.

Zakaria, F. (1997). The Rise of Illiberal Democracy. Foreign Affairs, 76(6), 22-43. Retrieved from https://msuweb.montclair.edu/ lebelp/FZakariallliberalDemocracy1997.pdf

Zakaria, F. (2007). The Future of Freedom. Illiberal Democracy at Home and Abroad. New York, NY: W.W. Norton. 